\title{
Highly organosoluble and transparent polyamides containing cyclohexane and trifluoromethyl moieties: Synthesis and characterization
}

\author{
P. H. Li, C. Y. Wang, G. Li*, J. M. Jiang \\ State Key Laboratory for Modification of Chemical Fibers and Polymer Materials College of Material Science and Engi- \\ neering, Donghua University, Shanghai 201620, China
}

Received 6 July 2009; accepted in revised form 19 August 2009

\begin{abstract}
New aromatic diamine with cyclohexane moiety substituted with trifluoromethyl group in the side chain, 4,4'(cyclohexane-1,4-diylbis(oxy))bis(3-(trifluoromethyl)aniline) (2), was successfully synthesized through the Williamson reaction of 1,4-cyclohexanediol and 2-chloro-5-nitrobenzotrifluoride, to yield the intermediate dinitro compound 1, followed by catalytic reduction with hydrazine and $\mathrm{Pd} / \mathrm{C}$ to afford the diamine $\mathbf{2}$. This diamine monomer leads to a series of organic-soluble polyamides $(\mathbf{4 a}-\mathbf{d})$ when reacted with different commercially available aromatic diacids (a-d) via a direct polycondensation with triphenyl phosphite and pyridine. The resulting polymers had inherent viscosities ranging from 0.89 to $1.29 \mathrm{dl} / \mathrm{g}$. All the polymers showed outstanding solubility and could be easily dissolved in amide-type polar aprotic solvents and even dissolved in less polar solvents. All the polymers formed transparent, strong, and flexible films with tensile strengths of 54-68 MPa, Young's moduli of 1.6-1.9 GPa, and elongations at break of 13.3-15.5\%. These polyamide films have low dielectric constants of 2.15-2.88 at $1 \mathrm{MHz}$ and low water absorptions of 1.96-2.84\%. Wide-angle X-ray diffraction measurements revealed that these polyamides were amorphous in nature.
\end{abstract}

Keywords: polymer synthesis, molecular engineering, solubility, optical transparency, dielectric constant

\section{Introduction}

Commercial wholly aromatic polyamides have been well known for their high temperature stability, excellent mechanical strength and good chemical resistance, which qualify them as high-performance polymeric materials [1-8]. However, these wholly aromatic polyamides usually shows poor solubility in common organic solvents and their extremely high melting temperatures, which lie above their decomposition temperatures, give rise to processing difficulties and so limit their applications. In order to overcome these drawbacks, considerable efforts have been made to modify their chemical structure to improve processability and solubility, so that to facility their use in a specific field. There are various approaches for improvement of the solubility and processability of polyamides without sacrificing their high thermal stability and mechanical properties, such as, the incorporation of the flexible linkages (e.g. -O-, $-\mathrm{SO}_{2}-$, etc.) $[9,10]$, cardo groups (such as cyclododecylidene, pyrene, and naphthalene, etc.) [11-13], or molecular asymmetry (ortho, meta versus linkages) [14-16] into the backbone or addition of bulky side group (such as tert-butyl, norbornane units) [17-21]. For example, the bis(ether amine)s and its aromatic polymer with cyclohexane group was synthesized and showed solubility in organic and polar solvents [22, 23]. Moreover, it was also proved that polyamides with trifluoromethyl-sub- 
stituted benzene in the side chain could enhance the solubility, reduce dielectric constant and moisture absorption, and raise the optical transparency [24-30]. Therefore, this work is focused on the synthesis of a new $\mathrm{CF}_{3}$-containing aromatic diamine 2 with cyclohexane moiety, and the preparation of fluorinated polyamides polycondensed with various diacids (a-d). The basic properties of the fluorinated polyamides were investigated.

\section{Experimental section}

\subsection{Materials}

1,4-cyclohexanediol (cis+trans, 98+\%, from Alfa Aesar), 2-chloro-5-nitrobenzotrifluoride (98\%, from ACROS), sodium hydride (60\%, from Alfa Aesar) as well as $10 \% \mathrm{Pd} / \mathrm{C}$ (from MERCK) were used as received. Commercially obtained anhydrous calcium chloride $\left(\mathrm{CaCl}_{2}\right)$ was dried under vacuum at $180^{\circ} \mathrm{C}$ for $8 \mathrm{~h}$. Reagent-grade aromatic dicarboxylic acids such as terephthalic acid (TPA), isophthalic acid (IPA), 4,4'-oxydibenzoic acid (OBA) and, 2,2-bis(4-carboxy-phenyl)hexafluoropropane (6FA) were purified by recrystallization. $N$-Methy-2-pyrrolidone (NMP), Pyridine (Py), $\mathrm{N}, \mathrm{N}$-dimethylacetamide (DMAc), $\mathrm{N}, \mathrm{N}$-dimethylformamide (DMF) and triphenyl phosphite (TPP) all from Alfa were purified by distillation under reduced pressure over calcium hydride. All other chemicals and solvents were reagent-grade and used without further purification unless otherwise noted.

\subsection{Monomer synthesis}

\subsubsection{Synthesis of 1,4-bis(4-nitro-2-}

(trifluoromethyl)phenoxy)cyclohexane (1)

$\mathrm{NaH}(6.4 \mathrm{~g}, 0.16 \mathrm{~mol})$ was firstly placed into a $250 \mathrm{ml}$, three-necked round-bottom flask equipped with a mechanical stirrer, $\mathrm{N}_{2}$ inlet, and dropping funnel. A mixture of 1,4-cyclohexanediol $(6.5 \mathrm{~g}$, $0.056 \mathrm{~mol})$ and $N, N$-dimethylformamide $(50 \mathrm{ml})$ was added dropwise through the dropping funnel at $0^{\circ} \mathrm{C}$. After stirring at $0^{\circ} \mathrm{C}$ for 2 hours, the mixture of 2-chloro-5-nitrobenzotrifluoride (25.9 g, $0.115 \mathrm{~mol}$ ) and $N, N$-dimethylformamide $(50 \mathrm{ml})$ was then added dropwise, and the reaction mixture was stirred at $5^{\circ} \mathrm{C}$ for 20 hours. Then the mixture was poured into $300 \mathrm{ml}$ distilled water. Some yellow solids precipitated out which were filtered and washed with ethanol for several times. The crude product obtained was recrystallized from DMF/ ethanol to give fine, light yellow crystals $(20.07 \mathrm{~g}$, $72.5 \%$ ). The properties of the product were found to be as follow. Melting point: $247-248^{\circ} \mathrm{C}$ [differential scanning calorimetry (DSC) at a scanning rate of $10^{\circ} \mathrm{C} / \mathrm{min}$ ]. FT-IR (KBr): 1518, 1333 $\left(\mathrm{C}-\mathrm{NO}_{2}\right.$ stretching); 1286, 1211, 1140, $1117 \mathrm{~cm}^{-1}$ (C-O and $\mathrm{C}-\mathrm{F}$ stretching). ${ }^{1} \mathrm{HNMR}\left(\mathrm{CDCl}_{3}, \delta\right)$ : $8.56\left(\mathrm{~d}, J=2.57 \mathrm{~Hz}, 2 \mathrm{H}, \mathrm{H}_{1}\right), 8.45\left(\mathrm{dd}, J_{1}=\right.$ $\left.9.18 \mathrm{~Hz}, J_{2}=2.65 \mathrm{~Hz}, 2 \mathrm{H}, \mathrm{H}_{2}\right), 7.14(\mathrm{~d}, J=$ $\left.9.24 \mathrm{~Hz}, 2 \mathrm{H}, \mathrm{H}_{3}\right), 4.96\left(\mathrm{~s}, 2 \mathrm{H}, \mathrm{H}_{4}\right), 2.15(\mathrm{~m}, 2 \mathrm{H}$, $\left.\mathrm{H}_{5}\right), 2.03\left(\mathrm{~m}, 4 \mathrm{H}, \mathrm{H}_{6}\right)$. Elemental analysis $\left(\mathrm{C}_{20} \mathrm{H}_{16} \mathrm{~F}_{6} \mathrm{~N}_{2} \mathrm{O}_{6}\right)$ : Calcd. C, $48.59 \% ; \mathrm{H}, 3.26 \%$; , $5.67 \%$. Found C, 49.01\%; H, 3.45\%; N, 5.94\%.

\subsubsection{Synthesis of 4,4'-(cyclohexane-1,4- diylbis(oxy))bis(3- (trifluoromethyl)aniline) (2)}

The purified dinitro compound $\mathbf{1}$ (14.8 g, $0.03 \mathrm{~mol}$ ), $0.3 \mathrm{~g}$ of $10 \% \mathrm{Pd} / \mathrm{C}$ and $100 \mathrm{ml}$ ethanol were taken into a three-necked flask and hydrazine monohydrate $(15 \mathrm{ml})$ was added dropwise over a period of $30 \mathrm{~min}$ at $80^{\circ} \mathrm{C}$. Upon completing addition, the mixture was heated at the reflux temperature for another $3 \mathrm{~h}$. The reaction solution was filtered hot to remove $\mathrm{Pd} / \mathrm{C}$ and the obtained solution was concentrated. Then the precipitated white solid was filtered and washed with ethanol to yield white crystals (11.1 g, 85.1\%).

The properties of the crystals were found to be as follows. Melting point: $156-157^{\circ} \mathrm{C}$ (differential scanning calorimetry (DSC) at a scan rate of $\left.10^{\circ} \mathrm{C} / \mathrm{min}\right)$. FT-IR (KBr): 3460, 3436, 3357, $(\mathrm{N}-\mathrm{H}$ stretching); 1259, 1236, 1217, $1146 \mathrm{~cm}-1(\mathrm{C}-\mathrm{O}$ and $\mathrm{C}-\mathrm{F}$ stretching). ${ }^{1} \mathrm{HNMR}$ (DMSO- $d_{6}, \delta$ ): 7.02 $\left(\mathrm{d}, J=8.83 \mathrm{~Hz}, 2 \mathrm{H}, \mathrm{H}_{1}\right), 6.83(\mathrm{~d}, J=2.70 \mathrm{~Hz}, 2 \mathrm{H}$, $\left.\mathrm{H}_{2}\right), 6.78\left(\mathrm{dd}, J_{1}=8.74 \mathrm{~Hz}, J_{2}=2.59 \mathrm{~Hz}, 2 \mathrm{H}, \mathrm{H}_{3}\right.$ ), 5.15 (brs, 4H, - $\left.\mathrm{NH}_{2}\right), 4.45\left(\mathrm{~s}, 2 \mathrm{H}, \mathrm{H}_{4}\right) 1.93$ (d, $\left.J=8.29 \mathrm{~Hz}, 4 \mathrm{H}, \mathrm{H}_{5}\right), 1.58\left(\mathrm{~m}, 4 \mathrm{H}, \mathrm{H}_{6}\right)$. Elemental analysis $\left(\mathrm{C}_{20} \mathrm{H}_{20} \mathrm{~F}_{6} \mathrm{~N}_{2} \mathrm{O}_{2}\right)$ : Calcd. C, 55.30\%; $\mathrm{H}$, 4.64\%; N, 6.45\%; Found C, 55.92\%; H, 4.98\%; N, $6.74 \%$.

\subsection{Polymer synthesis}

A generally synthetic procedure for the polyamides was described as follows: A mixture of $(0.6516 \mathrm{~g}$, $1.5 \mathrm{mmol}$ ) of diamine $2,4,4^{\prime}$-oxydibenzoic acid (C) 
(0.3875 g, $1.5 \mathrm{mmol}), 0.45 \mathrm{~g}$ of calcium chloride, $1.8 \mathrm{ml}$ of TPP, $1.0 \mathrm{ml}$ of pyridine, and $6 \mathrm{ml}$ of NMP was heated in nitrogen with stirring at $120^{\circ} \mathrm{C}$ for $3 \mathrm{~h}$. As the polycondensation proceeded, the reaction mixture became viscous gradually. The resultant solution of the polymer was poured slowly into $400 \mathrm{ml}$ of stirred methanol giving rise to a tough, fiber-like polymer precipitate. The precipitate was collected, washed with hot ethanol for three times and dried at $160^{\circ} \mathrm{C}$ under vacuum for $6 \mathrm{~h}$ to give $4 \mathrm{c}$ $(1.03 \mathrm{~g}, 95 \%)$. FT-IR (film): $3305 \mathrm{~cm}^{-1}(\mathrm{~N}-\mathrm{H}$ stretching), $1653 \mathrm{~cm}^{-1}$ (C=O stretching), $1246 \mathrm{~cm}^{-1}$ (C-O stretching), 1137, $1171 \mathrm{~cm}^{-1}$ (C-F stretching). ${ }^{1} \mathrm{HNMR}\left(\mathrm{DMSO}-d_{6}, \delta\right): 10.34\left(\mathrm{~s}, 2 \mathrm{H}, \mathrm{H}_{7}\right)$, $8.12\left(\mathrm{~s}, 2 \mathrm{H}, \mathrm{H}_{1}\right), 8.06$ (d, $\left.J=8.44,4 \mathrm{H}, \mathrm{H}_{9}\right), 7.97$ (d, $\left.J=7.24,2 \mathrm{H}, \mathrm{H}_{2}\right), 7.37\left(\mathrm{~d}, J=9.24,2 \mathrm{H}, \mathrm{H}_{3}\right), 7.23$ $\left(\mathrm{d}, J=8.00,4 \mathrm{H}, \mathrm{H}_{8}\right), 4.79\left(\mathrm{~s}, 2 \mathrm{H}, \mathrm{H}_{4}\right), 1.99$ (m, 4H, $\left.\mathrm{H}_{5}\right), 1.74\left(\mathrm{~d}, 4 \mathrm{H}, J=3.20, \mathrm{H}_{6}\right)$.

\subsection{Measurements}

${ }^{1}$ HNMR spectra were performed on a Bruker AV400 instrument with dimethyl sulfoxide (DMSO- $d_{6}$ ) or $\mathrm{CDCl}_{3}$ as the solvent and tetramethylsilane (TMS) as an internal standard. FT-IR spectra were recorded on a Nicolet Magna 470 spectrometer. Ultraviolet-visible (UV-vis) spectra of the polymer films $(\sim 10 \mu \mathrm{m}$ thickness $)$ were recorded on a Lambda 35 (Perkin Elmer) spectrophotometer at room temperature. Elemental analysis was carried out on a Carlo Erba1106 system. Differential scanning calorimetry (DSC) analysis was performed on a PE Diamond DSC instrument at a heating rate of $10^{\circ} \mathrm{C} / \mathrm{min}$ in nitrogen atmosphere. Glass transition temperatures $\left(T_{g}\right)$ were read at the middle of the transition in the heat capacity from the second heating scan. Thermogravimetric analysis (TGA) of the polymer samples was measured on a Netzsch TG 209F1 instrument at a heating rate of $20^{\circ} \mathrm{C} / \mathrm{min}$ in nitrogen atmosphere, and $T_{10}$ is reported as the temperatures where $10 \%$ weight losses was observed. Inherent viscosities $\left(\eta_{\text {inh }}=\ln \eta_{r} / c\right)$ were measured at a concentration of $0.5 \mathrm{~g} / \mathrm{dl}$ in DMAc at $30^{\circ} \mathrm{C}$ with an Ubbelohde viscometer. Mechanical properties of the films were investigated with an AGS-500ND tensile tester at a crosshead speed of $5 \mathrm{~mm} / \mathrm{min}$. An average of at least five individual specimens was used. Wide-angle X-ray diffraction (WAXD) was conducted on a Rigaku D/Max-2550PC X-ray dif- fraction with $\mathrm{Cu} / \mathrm{K}_{\alpha 1}$ radiation, operated at $40 \mathrm{kV}$ and $300 \mathrm{~mA}$. The dielectric constants (round shape samples, $D=15 \mathrm{~mm}$ ) were measured on a HP4291B at a frequency region of $1 \mathrm{MHz}-1.1 \mathrm{GHz}$ and $25^{\circ} \mathrm{C}$. The equilibrium water uptake was determined by the weighing of the changes in vacuum-dried film specimens before and after immersion in deionized water at $25^{\circ} \mathrm{C}$ for three days.

\section{Results and discussion}

\subsection{Monomers synthesis and characterization}

The new $\mathrm{CF}_{3}$-subsititued bis (ether amine) 2 was prepared in a two-step reaction process as shown in Figure 1. The first step is the Williamson reaction of 2-chloro-5-nitrobenzotrifluoride with 1,4-cyclohexanediol in anhydrous DMF in the presence of sodium hydride. The target diamine $\mathbf{2}$ was obtained by the catalytic reduction of $\mathbf{1}$ with hydrazine hydrate and $\mathrm{Pd} / \mathrm{C}$ catalyst in refluxing ethanol. The structure of the dinitro compound $\mathbf{1}$ and the diamine monomer $\mathbf{2}$ were investigated by elemental analysis as well as FT-IR and ${ }^{1}$ HNMR spectroscopy. The FT-IR spectra of dinitro compound $\mathbf{1}$ and diamine $\mathbf{2}$ are showed in Figure 2. The nitro groups in compound $\mathbf{1}$ gave two characteristic bands at 1518 and $1333 \mathrm{~cm}^{-1}\left(-\mathrm{NO}_{2}\right.$ asymmetric and symmetric stretching). After reduction, the characteristic absorptions of the nitro group disappeared, and the amino group occurred at bands in $3300-3500 \mathrm{~cm}^{-1}$ showing typical of $\mathrm{N}-\mathrm{H}$ stretching. Figure 3 illustrates the ${ }^{1} \mathrm{HNMR}$ spectra of dinitro compound $\mathbf{1}$ and diamine $\mathbf{2}$ respectively. From the ${ }^{1}$ HNMR spectra $\mathbf{1}$ and $\mathbf{2}$, the absorption signals
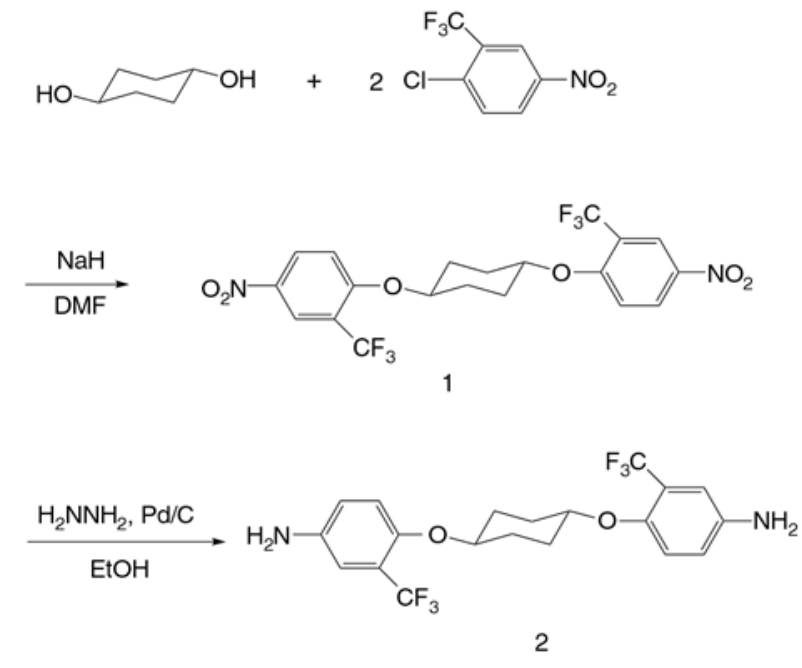

Figure 1. Synthetic route to the diamine monomer 2 


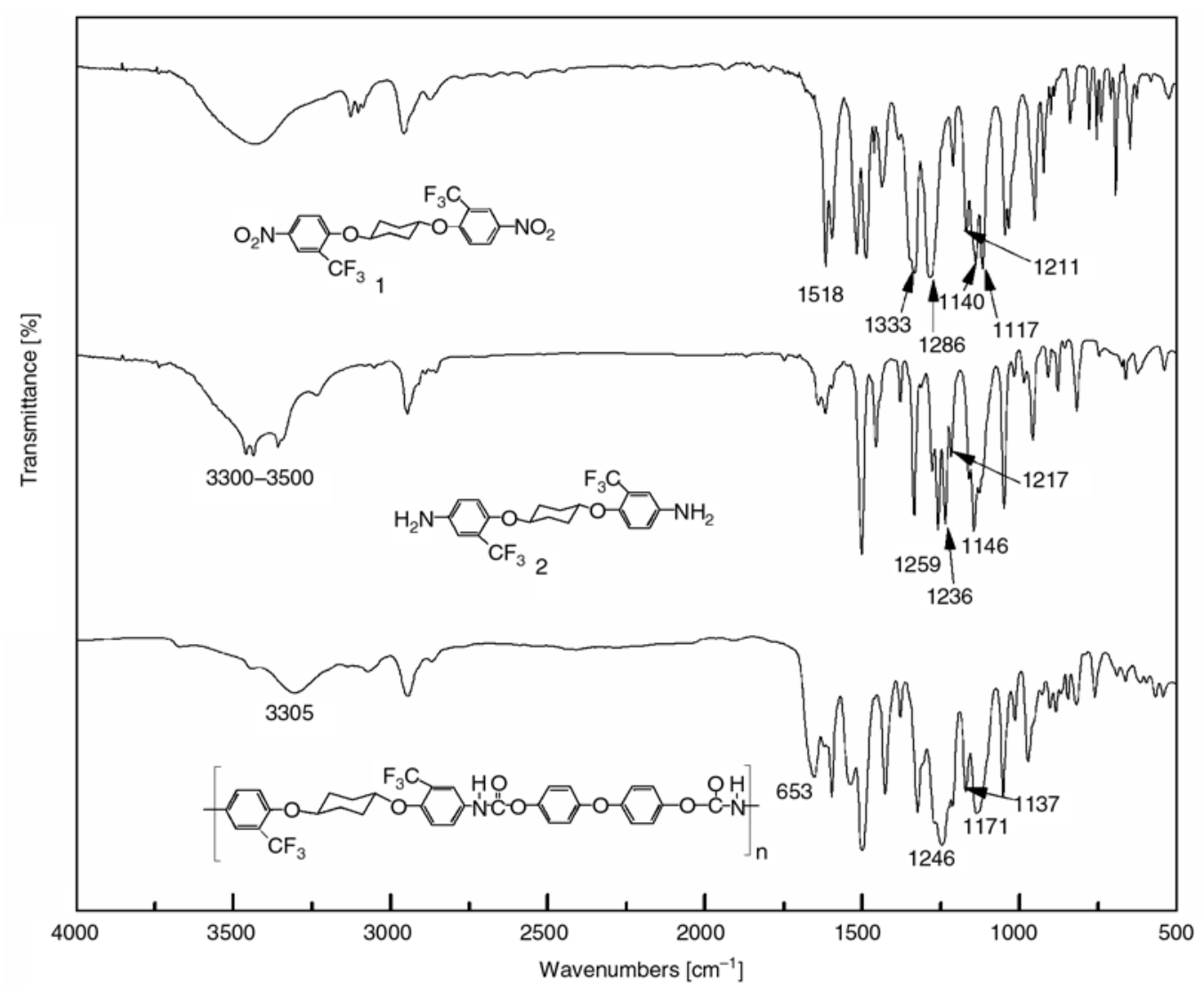

Figure 2. FT-IR spectra of dinitro 1 , diamine 2 and polyamide $\mathbf{4 c}$

of aromatic and cyclohexane protons of $\mathbf{1}$ appeared in the region of 7.14-8.56 and 2.03-4.96 ppm respectively; and those of $\mathbf{2}$ shifted to a higher field between $6.78-7.02$ and $1.58-4.45 \mathrm{ppm}$ respectively. The protons $\mathrm{H}_{1}$ of $\mathbf{1}$ resonated at the farthest downfield, which is due to the inductive effect of electron withdrawing of $-\mathrm{NO}_{2}$ and $-\mathrm{CF}_{3}$ groups. And the protons $\mathrm{H}_{3}$ and $\mathrm{H}_{4}$ affected by the electron donating behavior of ether group shifted to the upfield. After reduction, the $\mathrm{H}_{1}$ and $\mathrm{H}_{2}$ of 2 shifted to the upfield because of the electron-donating property of the amino group.

\subsection{Polymer synthesis}

Polyamides were prepared by Yamazaki-Higashi phosphorylation polyamidation technique [31]. Diamine 2 was polymerized with four different aromatic dicarboxylic acids-TPA, IPA, OBA, and 6FA to produce polyamides $\mathbf{a}, \mathbf{b}, \mathbf{c}$, and $\mathbf{d}$, respectively (Figure 4). The inherent viscosities (Table 1) of the polyamides are in the range of $0.89-1.29 \mathrm{dl} / \mathrm{g}$. The structures of polyamides were confirmed by elemental analysis, FT-IR and ${ }^{1}$ HNMR spectroscopies. The results of the elemental analyses (Table 1) were almost in good agreement with the calculated values of the proposed structures.

Table 1. Inherent viscosity and elemental analysis of polyamides

\begin{tabular}{|c|c|c|c|c|c|c|}
\hline \multicolumn{2}{|c|}{ Polyamides } & \multicolumn{5}{|c|}{ Elemental analysis [\%] of polyamides } \\
\hline Code & $\eta_{\text {inh }}{ }^{\mathbf{a}}[\mathbf{d l} / \mathbf{g}]$ & Formula (formula weight) & & $\mathbf{C}$ & $\mathbf{H}$ & $\mathbf{N}$ \\
\hline \multirow{2}{*}{ 4a } & \multirow{2}{*}{0.90} & $\left(\mathrm{C}_{30} \mathrm{H}_{28} \mathrm{~F}_{6} \mathrm{~N}_{2} \mathrm{O}_{4}\right)_{\mathrm{n}}$ & Calcd & 60.60 & 4.75 & 4.71 \\
& & $(594.54)_{\mathrm{n}}$ & Found & 59.71 & 4.68 & 4.77 \\
\hline \multirow{2}{*}{ 4b } & \multirow{2}{*}{0.89} & $\left(\mathrm{C}_{30} \mathrm{H}_{28} \mathrm{~F}_{6} \mathrm{~N}_{2} \mathrm{O}_{4}\right)_{\mathrm{n}}$ & Calcd & 60.60 & 4.75 & 4.71 \\
& & $(594.54)_{\mathrm{n}}$ & Found & 59.57 & 4.62 & 4.74 \\
\hline \multirow{2}{*}{ 4c } & \multirow{2}{*}{1.29} & $\left(\mathrm{C}_{36} \mathrm{H}_{32} \mathrm{~F}_{6} \mathrm{~N}_{2} \mathrm{O}_{5}\right)_{\mathrm{n}}$ & Calcd & 62.97 & 4.70 & 4.08 \\
& \multirow{2}{*}{ 4d } & $(686.64)_{\mathrm{n}}$ & Found & 62.04 & 4.63 & 4.01 \\
\hline \multirow{2}{*}{1.18} & $\left(\mathrm{C}_{39} \mathrm{H}_{32} \mathrm{~F}_{12} \mathrm{~N}_{2} \mathrm{O}_{4}\right)_{\mathrm{n}}$ & Calcd & 57.08 & 3.93 & 3.41 \\
& & $(820.66)_{\mathrm{n}}$ & Found & 55.72 & 3.87 & 3.35 \\
\hline
\end{tabular}

${ }^{\mathrm{a}}$ Measured at a concentration of $0.5 \mathrm{~g} / \mathrm{dl}$ in DMAc at $30^{\circ} \mathrm{C}$ 

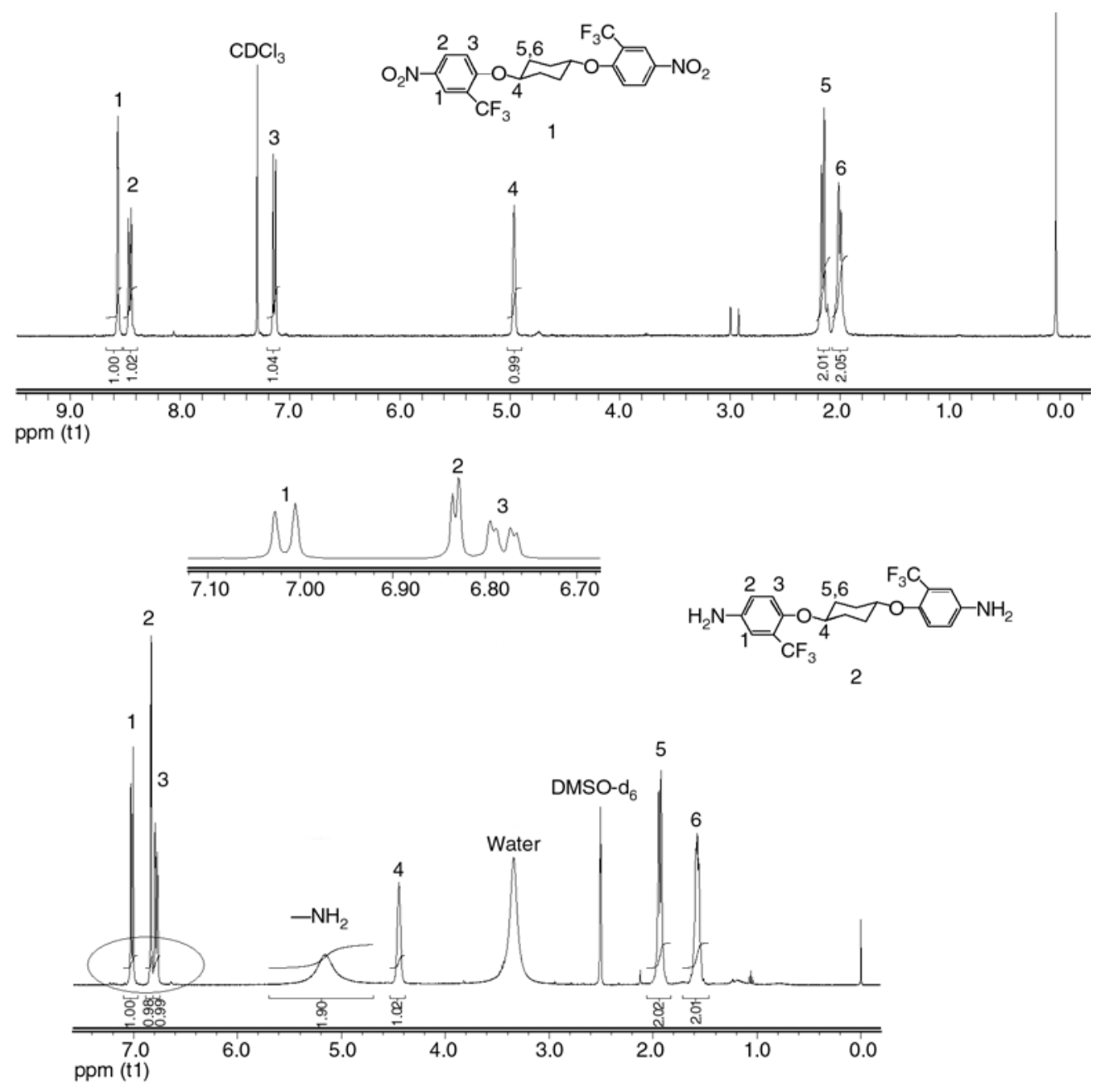

Figure 3. The ${ }^{1} \mathrm{HMNR}$ spectra of dinitro $\mathbf{1}$ and diamine $\mathbf{2}$
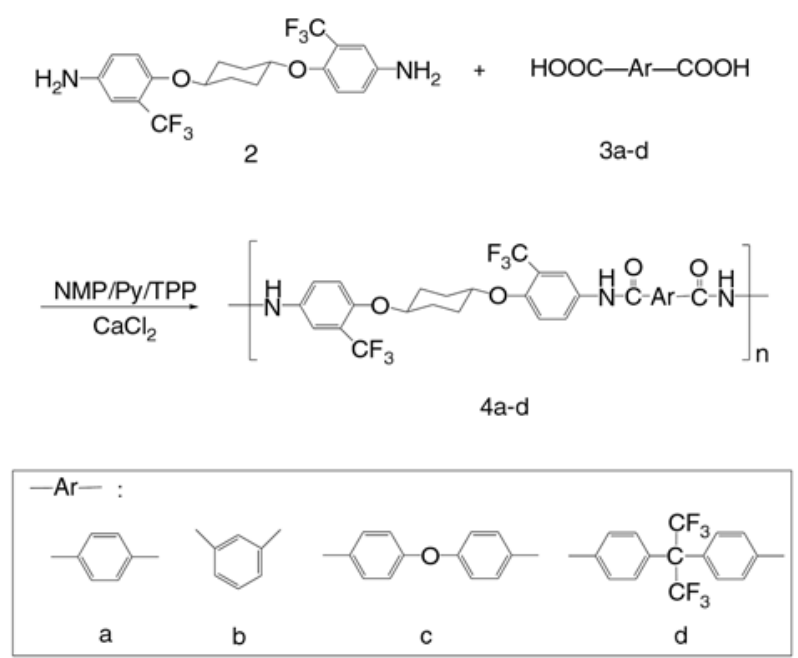

Figure 4. Synthesis of the fluorinated polyamides

The FT-IR spectra of the polyamides showed the characteristic absorptions around $3300 \mathrm{~cm}^{-1}$ and $1658 \mathrm{~cm}^{-1}$, which are characteristic of $\mathrm{N}-\mathrm{H}$ stretching and carbonyl stretching $(\mathrm{C}=\mathrm{O})$, respectively. A strong absorption band was observed around
$1250 \mathrm{~cm}^{-1}$ due to the $\mathrm{C}-\mathrm{O}-\mathrm{C}$ linkage. In addition, the strong $\mathrm{C}-\mathrm{F}$ absorptions between 1000 and $1200 \mathrm{~cm}^{-1}$ are also found in all of the polymers.

All protons in $\mathbf{4 b}$ are identified as number, and their integral values are in good agreement with the anticipated proton numbers. Furthermore the formation of amide groups was verified by ${ }^{1} \mathrm{HNMR}$, the resonance signals of amide protons appeared at 810.34. Generally, the protons ortho-to the $-\mathrm{CF}_{3}$ group $\left(\mathrm{H}_{1}\right)$ appear at the farthest downfield in the spectra due to the effect of the electron-withdrawing $-\mathrm{CF} 3$ group. In Figure 5, the protons in the cyclohexane $\left(\mathrm{H}_{4}, \mathrm{H}_{5}, \mathrm{H}_{6}\right)$ all show absorptions at the farthest upfield area.

\subsection{Polymer solubility}

Table 2 summarizes the solubilities of the fluorinated polyamides. It can be seen that the obtained polyamides were soluble at a concentration of over $10 \%$ in the amide type solvents such as NMP, 


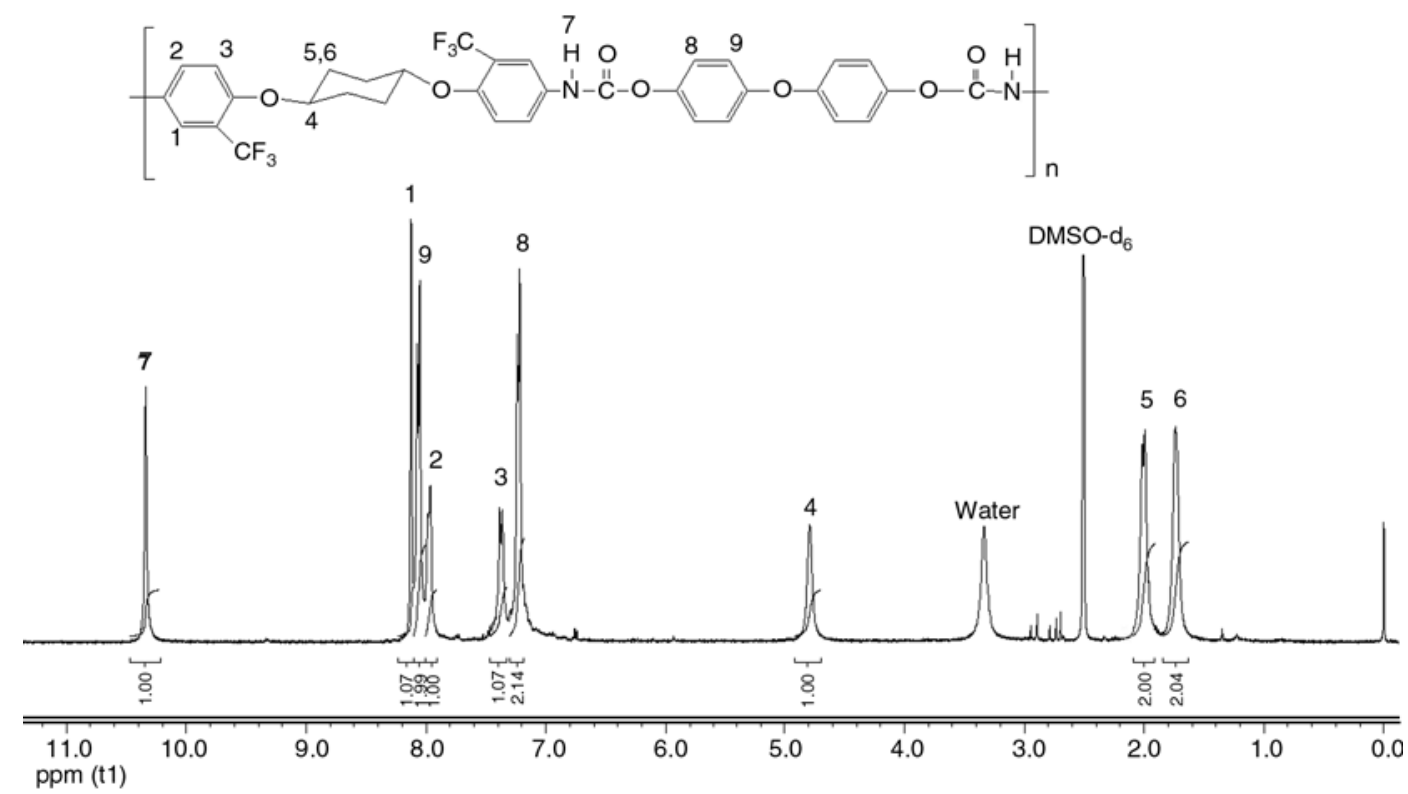

Figure 5. The ${ }^{1} \mathrm{HMNR}$ spectrum of $\mathbf{4 c}$ in DMSO- $d_{6}$

Table 2. Solubility behavior of the polyamides

\begin{tabular}{|c|c|c|c|c|c|c|c|c|}
\hline \multirow{2}{*}{ Polymersa } & \multicolumn{8}{|c|}{ Solvents $^{b}$} \\
\hline & NMP & DMAc & DMF & $\mathbf{P y}$ & DMSO & THF & Cy & $\mathrm{CH}_{2} \mathrm{Cl}_{2}$ \\
\hline $4 a$ & +++ & +++ & +++ & ++ & ++ & ++ & + & + \\
\hline $4 \mathrm{~b}$ & +++ & +++ & +++ & ++ & ++ & ++ & + & + \\
\hline $4 c$ & +++ & +++ & +++ & ++ & ++ & ++ & + & + \\
\hline $4 d$ & +++ & +++ & +++ & ++ & ++ & ++ & + & + \\
\hline
\end{tabular}

${ }^{\mathrm{a}}+++, 100 \mathrm{mg}$ sample dissolved in $1 \mathrm{ml}$ solvent $(10 \%) ;++$, soluble at $5 \% ;+$, soluble at $1 \%$

bAbbreviations: NMP - N-methyl-2-pyrrolidinone; DMAc - N,N-dimethylacetamide; DMF - N,N-dimethylformamide;

DMSO - dimethyl sulfoxide; Py - pyridine; THF - tetrahydrofuran; Cy - Cyclohexanone

DMAc, and DMF, 5\% in pyridine, DMSO and THF, and $1-5 \%$ in $\mathrm{CH}_{2} \mathrm{Cl}_{2}$ and cyclohexanone. Their good solubility and amorphous nature may be apparently due to the presence of the pendent trifluoromethyl groups and ether links in macromolecular chains, which might disrupt the interaction of polymer chains by enlarging the distance between polymer chains, thereby leading to a decrease in packing density and an increase in solubility. The excellent solubility could make these polyamides easy to be processed and benefit their practical applications.

\subsection{Mechanical and optical properties}

All the obtained polyamides could be readily processed to flexible, creasable, and essentially col- orless films by casting from solutions in DMAc. The tensile properties of the polyamides films are summarized in Table 3. Their tensile strengths, elongations at break, and initial moduli of polymer films were in the range of 54-68 MPa, 13.3-15.4\%, and 1.6-1.9 GPa, respectively. The optical performances of these fluorinated polymides films are also given in Table 3, and the UV-Vis spectra of these films, are shown in Figure 6. It can be seen from Table 3 that these fluorinated polyamides films exhibited good transparency, the UV cutoff wavelength $\left(\lambda_{\text {cut off }}\right)$ was in the range of 338 $357 \mathrm{~nm}$, and the transparency at $450 \mathrm{~nm}\left(T_{450}\right)$ was higher than $84 \%$. As expected, the introduction of bulky pendant groups effectively disrupt the dense packing of molecular chains and lead to low color and high optical transparent polymer films.

Table 3. Mechanical and optical properties of the polyamides films

\begin{tabular}{|c|c|c|c|c|c|}
\hline Polymer code & Tensile strength [MPa] & Tensile modulus [GPa] & Elongation at break [\%] & $\lambda_{\text {cut off }[\mathbf{n m}]}$ & T 450 [\%] $^{\text {[\% }}$ \\
\hline 4a & 54 & 1.6 & 13.3 & 357 & 84 \\
\hline 4b & 64 & 1.9 & 14.1 & 339 & 87 \\
\hline 4c & 68 & 1.6 & 15.5 & 335 & 86 \\
\hline 4d & 58 & 1.7 & 15.4 & 338 & 87 \\
\hline
\end{tabular}




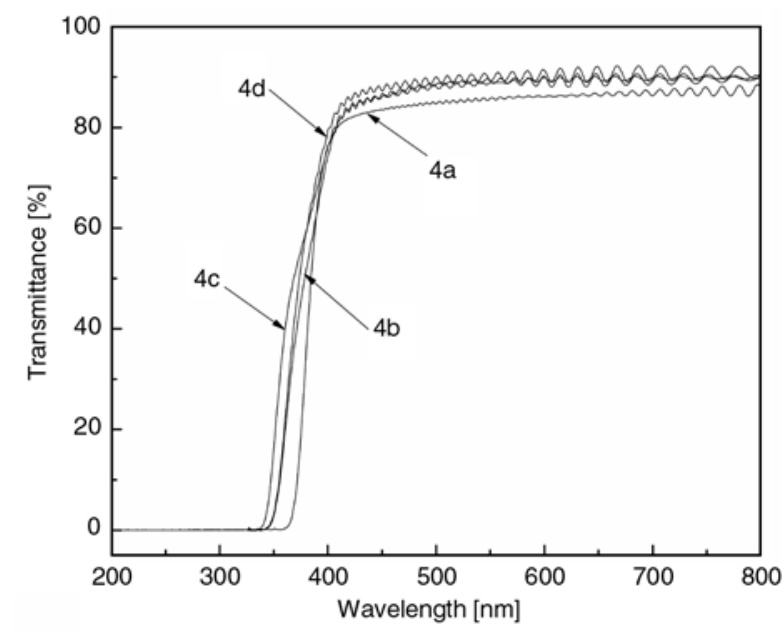

Figure 6. UV-visible spectra of the polyamide films

\subsection{Thermal properties}

The thermal properties of the polyamides were evaluated with TGA and DSC. The results are tabulated in Table 4. Owing to amorphous nature, the $T_{g}$ values of all the polyamides could be easily identified in the DSC traces. The values for the polyamides were found to be in the range of $203-225^{\circ} \mathrm{C}$, depending on the stucture of the chain flexibility and the $\mathrm{CF}_{3}$ hindrance of the polymer backbones Figure 7 presents typical TGA curves of

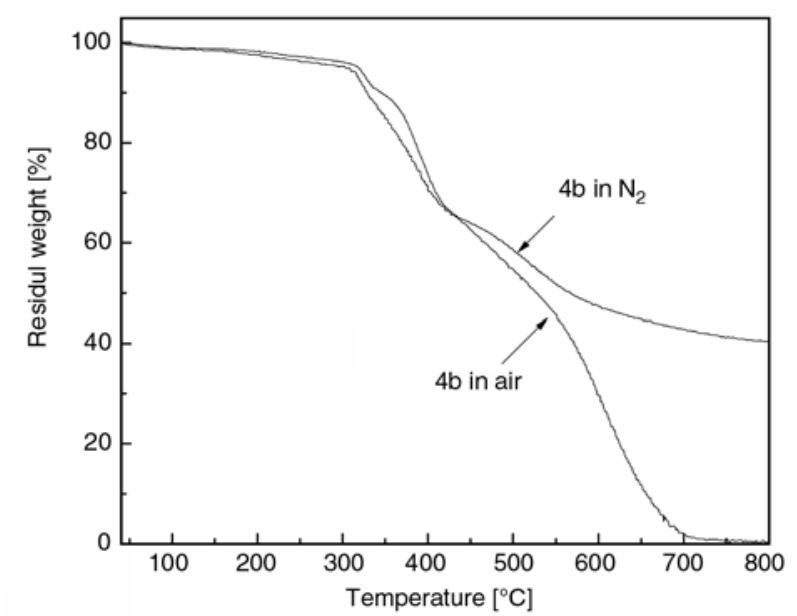

Figure 7. TGA curves of $\mathbf{3 b}$ at a heating rate of $20^{\circ} \mathrm{C} / \mathrm{min}$

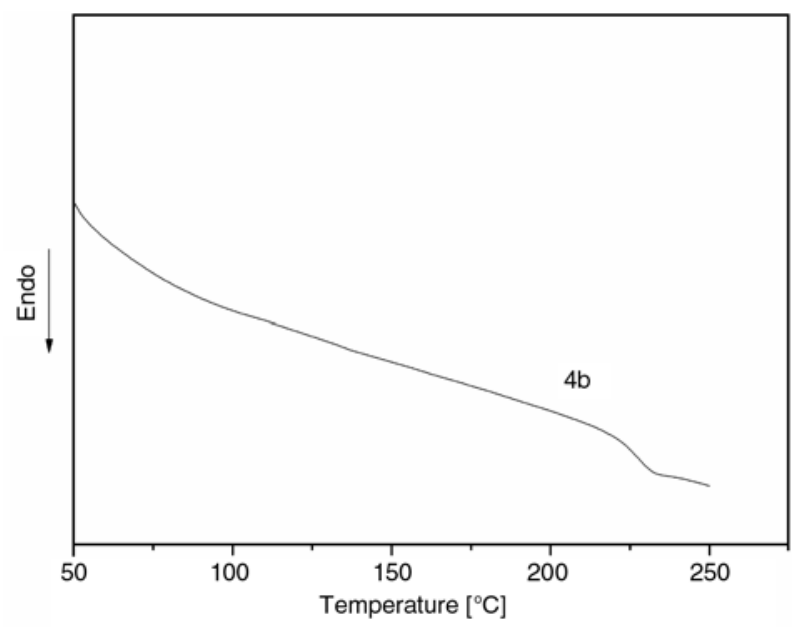

Figure 8. DSC curve of $\mathbf{4 b}$ in air at a scanning rate of $20^{\circ} \mathrm{C} / \mathrm{min}$

3b and the $10 \%$ weight loss temperature $\left(T_{10}\right)$ as well as the anaerobic char yield at $800^{\circ} \mathrm{C}$ in nitrogen were also summarized in Table 4. All the polymers exhibited good thermal stability. Figure 8 shows the DSC curve of $\mathbf{4 b}$ in air atmosphere. The $T_{10}$ of the polyamides stayed between $330-364^{\circ} \mathrm{C}$ in nitrogen and $308-350^{\circ} \mathrm{C}$ in air, onset decomposition temperature in the range of $330-342^{\circ} \mathrm{C}$, and the char yield of all the polyamides at $800^{\circ} \mathrm{C}$ were in the range of $40-42 \%$. It implied that these polyamides with trifluoromethyl groups in the polymer backbone showed good thermal stability.

\subsection{X-Ray diffraction of the polyamides}

The WAXD studies of polyamides $\mathbf{4 a - d}$ indicated that all of these polymers were essentially amorphous as showed in Figure 9. The obtained polymers displayed almost amorphous patterns in nature, this could be attributable to the presence of pendants which reduce attraction between molecules and hindrance macromolecular packing regularly. Generally, these polymers with similar struc-

Table 4. Thermal properties of polyamides

\begin{tabular}{|c|c|c|c|c|c|}
\hline $\begin{array}{c}\text { Polymer } \\
\text { code }\end{array}$ & $\begin{array}{c}\mathbf{T}_{\mathbf{g}}^{\mathbf{a}} \\
{\left[{ }^{\circ} \mathbf{C}\right]}\end{array}$ & $\begin{array}{c}\mathbf{T}_{\mathbf{d}}^{\mathbf{b}} \\
{\left[{ }^{\circ} \mathbf{C}\right]}\end{array}$ & $\mathbf{I n ~ N}_{\mathbf{2}}$ & $\mathbf{T}_{\mathbf{1 0}}{ }^{\mathbf{c}}\left[{ }^{\circ} \mathbf{C}\right]$ & $\mathbf{C h}^{\mathbf{I n} \text { Air }}$ \\
\hline $\mathbf{4 a}$ & 219 & 330 & 340 & 330 & 40 \\
\hline $\mathbf{4 b}$ & 225 & 331 & 345 & 331 & 41 \\
\hline $\mathbf{4 c}$ & 213 & 321 & 356 & 335 & 40 \\
\hline $\mathbf{4 d}$ & 224 & 342 & 364 & 350 & 42 \\
\hline
\end{tabular}

aFrom DSC measurements conducted at a heating rate of $10^{\circ} \mathrm{C} / \mathrm{min}$

${ }^{\mathrm{b}}$ Onset decomposition temperature in TGA at a heating rate of $20^{\circ} \mathrm{C} / \mathrm{min}$ in nitrogen atmosphere

${ }^{\mathrm{c}}$ Temperature at $10 \%$ weight loss $\left(T_{10}\right)$ were determined by TGA in nitrogen atmosphere at a heating rate of $20^{\circ} \mathrm{C} / \mathrm{min}$

${ }^{\mathrm{d}}$ Residual weight $[\%]$ at $800^{\circ} \mathrm{C}$ in nitrogen 
Table 5. Dielectric constant and water absorption of various fluorinated polyamides films

\begin{tabular}{|c|c|c|c|c|c|c|}
\hline \multirow{2}{*}{$\begin{array}{l}\text { Polymer } \\
\text { code }\end{array}$} & \multirow{2}{*}{$\begin{array}{c}\text { Film thickness } \\
{[\mu \mathrm{m}]}\end{array}$} & \multicolumn{4}{|c|}{ Dielectric constant (dry) } & \multirow{2}{*}{$\begin{array}{c}\text { Water absorption } \\
{[\%]}\end{array}$} \\
\hline & & $1 \mathrm{MHz}$ & $10 \mathrm{MHz}$ & $100 \mathrm{MHz}$ & $1000 \mathrm{MHz}$ & \\
\hline $4 a$ & 53 & 2.25 & 2.10 & 2.07 & 2.05 & 2.33 \\
\hline $4 b$ & 63 & 2.88 & 2.82 & 2.78 & 2.75 & 2.57 \\
\hline $4 c$ & 47 & 2.77 & 2.59 & 2.56 & 2.52 & 2.84 \\
\hline 4d & 54 & 2.15 & 2.03 & 2.00 & 1.97 & 1.96 \\
\hline
\end{tabular}

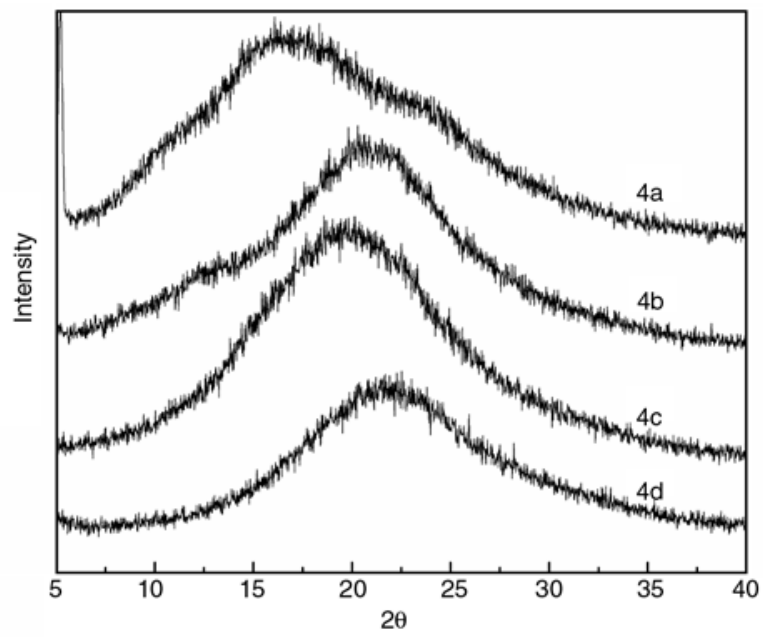

Figure 9. Wide-angle X-ray diffraction patterns of the polyamides

ture containing $-\mathrm{CF}_{3}$ groups are amorphous [32-35].

\subsection{Dielectric constant and water absorption}

Table 5 summmarizes the results of dielectric constants and moisture absorption. 4d showed lower dielectric constants of 2.15 at $1 \mathrm{MHz}$ than the others because of the higher fluorine content in the repeat unit. The decreased dielectric constants could be attributed to the presence of bulky $\mathrm{CF}_{3}$ groups, which resulted in the strong electronegativity of fluorine results in very low polarizability of $\mathrm{C}-\mathrm{F}$ bonds. In addition, the polymer also exhibited lower water absorptions (1.96-2.84\%) due to the hydrophobic nature of the trifluoromethyl groups. The low water absorptions also ensured that these polyamides possess stable dielectric performance.

\section{Conclusions}

A series of new organosoluble alicyclic polyamides containing trifluoromethyl and cyclohexane groups were prepared by polycondensation. The obtained polyamides show an excellent solubility in many solvents and they could be easily processed to flex- ible and tough films by casting of their solutions. These polyamides derived from diamine 2 exhibited amorphous nature, excellent optical properties, good mechanical properties, as well as good thermal stability. Moreover, these polyamides display low dielectric constants and water absorption; thus, these obtained polyamides possessed an eminent combination of several desired properties and could be used as potential high-temperature resistant materials for optical or microelectronic applications.

\section{Acknowledgements}

The authors would like to thank the National Natural Science Foundation of China (50673017) and Program of Introducing Talents of Discipline to Universities (111-2-04).

\section{References}

[1] Cassidy P. E.: Thermally stable polymers. Marcel Dekker, New York (1980).

[2] Yang H. H.: Aromatic high-strength fibers. Wiley, New York (1989).

[3] Tamami B., Yeganeh H.: Synthesis and characterization of novel aromatic polyamides derived from 4 aryl-2,6-bis(4-aminophenyl) pyridines. Polymer, 42, 415-420 (2001). DOI: $10.1016 / \mathrm{S} 0032-3861(00) 00276-7$

[4] Lee H. S., Kim S. Y.: Synthesis of poly(arylene ether amide)s containing $\mathrm{CF}_{3}$ groups by nitro displacement reaction of AB-type monomers. Macromolecular Rapid Communications, 23, 666-671 (2002).

DOI: 10.1002/1521-3927(20020801)23:12<665::AIDMARC665>3.0.CO;2-A

[5] Negi Y. S., Suzuki Y-I., Kawamura I., Kakimoto MA., Imai Y.: Synthesis and characterization of soluble polyamides based on 2,2-bis[4-(4-aminophenoxy) phenyl]hexafluoropropane and 2,2-bis[4-(4-aminophenoxy)phenyl]propane and diacid chlorides. Journal of Polymer Science Part A: Polymer Chemistry, 34, 1663-1668 (1996).

DOI: $10.1002 /(\mathrm{SICI}) 1099-0518(19960715) 34: 9$ $\leq 1663:$ :AID-POLA3>3.0.CO;2-T 
[6] Varma I. K., Kumar R., Bhattacharyya A. B.: Effect of structure on properties of aromatic polyamides. Journal of Applied Polymer Science, 40, 531-542 (1990). DOI: 10.1002/app.1990.070400319

[7] Wu S-C., Shu C-F.: Synthesis and properties of soluble aromatic polyamides derived from 2,2'-bis(4-carboxyphenoxy)-9,9'-spirobifluorene. Journal of Polymer Science Part A: Polymer Chemistry, 41, 11601166 (2003).

DOI: $10.1002 /$ pola.10657

[8] Liaw D-J., Liaw B-Y., Yang C-M.: Synthesis and properties of new polyamides based on bis[4-(4aminophenoxy)phenyl]diphenylmethane. Macromolecules, 32, 7248-7250 (1999).

DOI: $\underline{10.1021 / \mathrm{ma} 990545 \mathrm{~h}}$

[9] Mehdipour-Ataei S., Heidari H.: Synthesis and characterization of novel soluble and thermally stable polyamides based on pyridine monomer. Macromolecular Symposia, 193, 159-168 (2003).

DOI: $\underline{10.1002 / \text { masy.200390049 }}$

[10] Feger C., Khojasteh M. M., McGrath J. E.: Polyimides: materials, chemistry, and characterization. Elsevier, Amsterdam (1989).

[11] Liaw D-J., Liaw B-Y.: Synthesis and properties of new polyimides derived from 1,1-bis[4-(4-aminophenoxy)phenyl]cyclododecane. Polymer, 40, 3183-3189 (1999). DOI: $10.1016 / \mathrm{S} 0032-3861(98) 00494-7$

[12] Cheng L., Jian X. G., Mao S. Z.: Aromatic polyamides derived from unsymmetrical diamines containing the phthalazinone moiety. Journal of Polymer Science Part A: Polymer Chemistry, 40, 3489-3496 (2002). DOI: $10.1002 /$ pola. 10426

[13] Liaw D-J., Wang K-L., Chang F-C.: Novel organosoluble poly(pyridine-imide) with pendent pyrene group: Synthesis, thermal, optical, electrochemical, electrochromic, and protonation characterization. Macromolecules, 40, 3568-3574 (2007). DOI: $10.1021 / \mathrm{ma} 062546 \mathrm{x}$

[14] Yang C. P., Su Y. Y.: Properties of organosoluble aromatic polyimides from 3'-trifluoromethyl-3,4'-oxydianiline. Polymer, 44, 6311-6322 (2003). DOI: $10.1016 / \mathrm{S} 0032-3861(03) 00684-0$

[15] Eastmond G. C., Paprotny J., Irwin R. S.: Meltprocessable poly(ether imide)s based on catechol bis(ether anhydride). Macromolecules, 29, 1382-1388 (1996). DOI: $10.1021 / \mathrm{ma} 951007 \mathrm{~h}$

[16] Sciannamea V., Catala J-M., Jérôme R., Detrembleur C.: Controlled radical polymerization of styrene mediated by the $C$-phenyl- $N$-tert-butylnitrone/AIBN pair: Kinetics and electron spin resonance analysis. Journal of Polymer Science Part A: Polymer Chemistry, 45, 1219-1235 (2007).

DOI: $10.1002 /$ pola.21889
[17] Yang C-P., Hsiao S-H., Yang H-W.: Synthesis and characterization of aromatic polyamides based on a bis(ether-carboxylic acid) or a dietheramine derived from tert-butylhydroquinone. Macromolecular Chemistry and Physics, 200, 1528-1534 (1999).

DOI: 10.1002/(SICI)1521-3935(19990601)200:6 $\leq 1528::$ AID-MACP1528>3.0.CO;2-D

[18] Kim H-S., Kim Y-H., Ahn S-H., Kwon S-K.: Synthesis and characterization of highly soluble and oxygen permeable new polyimides bearing a noncoplanar twisted biphenyl unit containing tert-butylphenyl or trimethylsilyl phenyl groups. Macromolecules, 36, 2327-2332 (2003).

DOI: $10.1021 / \mathrm{ma} 0214557$

[19] Yang C-P., Lin J-H.: Syntheses and properties of aromatic polyamides and polyimides based on 3,3-bis[4(4-aminophenoxy)phenyl]-phthalimidine. Polymer, 36, 2607-2614 (1995).

DOI: $10.1016 / 0032-3861(95) 91208-\mathrm{O}$

[20] Espeso J. F., de la Campa J. G., Lozano A. E., de Abajo J.: Synthesis and characterization of new soluble aromatic polyamides based on 4-(1-adamantyl)-1, 3-bis(4-aminophenoxy)benzene. Journal of Polymer Science Part A: Polymer Chemistry, 38, 1014-1023 (2000).

DOI: $10.1002 /(\mathrm{SICI}) 1099-0518(20000315) 38: 6$ $\leq 1014:$ :AID-POLA11>3.0.CO;2-H

[21] Espeso J. F., Ferrero E., de la Campa J. G., Lozano A. E., de Abajo J.: Synthesis and characterization of new soluble aromatic polyamides derived from 1,4-Bis(4carboxyphenoxy)-2, 5-di-tert-butylbenzene. Journal of Polymer Science Part A: Polymer Chemistry, 39, 475-485 (2001).

DOI: $10.1002 / 1099-0518(20010215) 39: 4<475::$ AIDPOLA1016>3.0.CO;2-I

[22] Salamone J. C.: Polymeric material encyclopedia. CRC Press, New York (1996).

[23] Yang C-P., Chen R-S., Yu C-W.: Preparation and characterization of organosoluble polyimides based on 1,1-bis[4-(3,4-aminophenoxy)phenyl]cyclohexane and commercial aromatic dianhydrides. Journal of Applied Polymer Science, 82, 2750-2759 (2001). DOI: $10.1002 / a p p .2128$

[24] Takashi K., Atsushi S., Shoji T.: New aromatic diamine and polyimide. Japanese Patent 2000-297067, Japan (2000).

[25] Myung B. Y., Kim J. J., Yoon T. H.: Synthesis and characterization of novel 3,6-di[3',5'-bis(trifluoromethyl)phenyl]pyromellitic dianhydride for polyimide synthesis. Journal of Polymer Science Part A: Polymer Chemistry, 40, 4217-4227 (2002).

DOI: 10.1002/pola.10512

[26] Myung B. Y., Kim J. S., Kim J. J., Yoon T. H.: Synthesis and characterization of novel polyimides with 2,2-bis[4(4-aminophenoxy)phenyl]phthalein-3',5' bis(trifluoromethyl)anilide. Journal of Polymer Science Part A: Polymer Chemistry, 41, 3361-3374 (2003).

DOI: $\underline{10.1002 / \text { pola. } 10924}$ 
[27] Banerjee S., Madhra M. K., Salunke A. K., Jaiswal D. K.: Synthesis and properties of fluorinated polyimides. 3. Derived from novel 1,3-bis[3'-trifluoromethyl-4'(4"-amino benzoxy) benzyl] benzene and 4,4-bis[3'-trifluoromethyl-4'(4-amino benzoxy) benzyl] biphenyl. Polymer, 44, 613-622 (2003). DOI: $10.1016 / \mathrm{S} 0032-3861(02) 00801-7$

[28] Wang C-Y., Li P-H., Li G., Jiang J-M.: High optical transparency and low dielectric constant of novel organosoluble poly(ether ketone amide)s derived from an unsymmetrical diamine containing trifluoromethyl and methyl pendant groups. Colloid and Polymer Science, 287, 495-500 (2009).

DOI: $10.1007 / \mathrm{s} 00396-009-2007-2$

[29] Liaw D-J., Chen W-H., Hu C-K., Lee K-R., Lai J-Y.: High optical transparency, low dielectric constant and light color of novel organosoluble polyamides with bulky alicyclic pendent group. Polymer, 48, 65716580 (2007).

DOI: $10.1016 /$ j.polymer.2007.08.041

[30] Hsiao S-H., Yang C-P., Tsai C-Y., Liou G-S.: A novel class of organosoluble and light-colored fluorinated polyamides derived from 2,2'-bis(4-amino-2-trifluoromethylphenoxy)biphenyl or 2,2'-bis(4-amino-2-trifluoromethylphenoxy)-1,1'-binaphthyl. European Polymer Journal, 40, 1081-1094 (2004). DOI: $10.1016 /$ j.eurpolymj.2004.01.001
[31] Yamazaki N., Matsumoto M., Higashi F.: Studies on reactions of the $\mathrm{N}$-phosphonium salts of pyridines. XIV. Wholly aromatic polyamides by the direct polycondensation reaction by using phosphites in the presence of metal salts. Journal of Polymer Science: Polymer Chemistry Edition, 13, 1373-1380 (1975). DOI: $10.1002 /$ pol.1975.170130609

[32] Sheng S-R., Pei X-L., Huang Z-Z., Liu X-L., Song CS.: Novel soluble fluorinated aromatic polyamides derived from 2-(4-trifluoromethylphenoxy)terephthaloyl chloride with various aromatic diamines. European Polymer Journal, 45, 230-236 (2009). DOI: $\underline{10.1016 / j . e u r p o l y m j .2008 .10 .023}$

[33] Qiu Z., Wang J., Zhang Q., Zhang S., Ding M., Gao L.: Synthesis and properties of soluble polyimides based on isomeric ditrifluoromethyl substituted 1,4bis(4-aminophenoxy)benzene. Polymer, 47, 84448452 (2006).

DOI: $10.1016 /$ j.polymer.2006.10.031

[34] Liu B. J., Hu W., Chen C. H., Jiang Z. H., Zhang W. J., Wu Z. G., Matsumoto T.: Soluble aromatic poly(ether ketone)s with a pendant 3,5-ditrifluoromethylphenyl group. Polymer, 45, 3241-3247 (2004).

DOI: 10.1016/j.polymer.2004.03.015

[35] Yang C-P., Chen Y-P., Woo E. M: Thermal behavior of 1,4-bis(4-trimellitimido-2-trifluoromethyl phenoxy)benzene (DIDA) solvated with polar organic solvents and properties of DIDA-based poly(amideimide)s. Polymer, 45, 5279-5293 (2004).

DOI: 10.1016/j.polymer.2004.05.035 